\title{
A MODALIZAÇÃO \\ DISCURSIVA COMO ÍNDICE DE \\ ARGUMENTATIVIDADE \\ NOS GÊNEROS \\ ACADÊMICOS
}

\section{LA MODALIZACIÓN DISCURSIVA COMO ÍNDICE DE ARGUMENTATIVIDAD EN LOS GÉNEROS ACADÉMICOS}

DISCURSIVE MODALITY AS ARGUMENTATIVE INDEX IN ACADEMIC GENRES

\author{
Erivaldo Pereira do Nascimento* \\ Universidade Federal da Paraíba
}

RESUMO: O objetivo deste artigo é mostrar como a modalização discursiva funciona nos gêneros acadêmicos, imprimindo argumentatividade, ou seja, orientando os enunciados em razão de determinadas conclusões. Trata-se de reflexões feitas sobre o fenômeno da modalização nos referidos gêneros, a partir de investigações científicas de natureza qualitativa e de caráter descritivo e interpretativista. Para tal, fundamentamo-nos nos estudos sobre a Modalização Discursiva, a partir de Cervoni (1989), Castilho e Castilho (1993), Koch (2012), Nascimento (2009, 2010) e Nascimento e Silva (2012), além dos estudos sobre a argumentação linguística de Ducrot $(1987,1988)$. A descrição do fenômeno da modalização nos gêneros investigados permitiu-nos verificar que a modalização é uma estratégia presente em todos eles (ata administrativo-acadêmica, resumo, resenha, projeto de pesquisa de TCC, monografia de TCC e artigo científico) e que é utilizada com diferentes funções discursivas, produzindo diversos efeitos de sentido: assimilação, distanciamento e avaliação.

PALAVRAS-CHAVE: Modalização. Argumentação. Gêneros Acadêmicos.

RESUMEN: Este artículo tiene el objetivo de mostrar como la modalización discursiva funciona en los géneros académicos, imprimiendo argumentación, es decir, direccionando los enunciados a determinadas conclusiones. Se hacen reflexiones sobre el fenómeno de la modalización en dichos géneros, a partir de investigaciones de naturaleza cualitativa, de carácter descriptivo e

\footnotetext{
* Doutor em Letras pela UFPB e estagiário de Pós-Doutorado pela UBA-Argentina. Professor Associado da UFPB, atuando no Programa de Pós-Graduação em Linguística (PROLING) e no Programa de Mestrado Profissional em Letras (PROFLETRAS). E-mail: <ery.nascimento2008@gmail.com>.
} 
interpretativo. Está fundamentado en los estudios sobre modalización discursiva de Cervoni (1989), Castilho \& Castilho (1993), Koch (2012), Nascimento $(2009,2010)$ y Nascimento \& Silva (2012), además de los estudios sobre la argumentación lingüística en la perspectiva de Ducrot $(1987,1988)$, entre otros. La descripción de la modalización en los géneros investigados posibilitó verificar que este fenómeno es una estrategia presente en todos ellos: acta administrativo-académica, resumen, reseña académica, proyecto de investigación, monografía y artículo científico. Además, es utilizada con distintas funciones discursivas, produciendo diferentes efectos de sentido: asimilación, alejamiento y evaluación.

PALABRAS CLAVE: Modalización. Argumentación. Géneros Académicos.

ABSTRACT: This study aims to show how modality behaves in the academic genres, producing argumentation. In other words, driving utterances to a specific conclusion. This work is composed of reflections about the modality phenomenon in academic genres, deriving from qualitative, descriptive and interpretative scientific investigations. It is also based on the studies about Discursive Modality proposed by Cervoni (1989), Castilho \& Castillho (1993), Koch (2012), Nascimento (2009, 2010), and Nascimento \& Silva (2012), as well as the study about linguistic argumentation by Ducrot (1987, 1988). Modality was found in all the genres investigated (administrative-academic protocol, abstract, review, undergraduate research project, undergraduate monograph, and academic paper), and is used with different discursive functions: assimilation, detachment and evaluation.

KEYWORDS: Modality. Argumentation. Academic Genres.

\section{INTRODUÇÃO}

Este artigo apresenta uma reflexão a respeito do funcionamento da modalização discursiva em diferentes gêneros acadêmicos e objetiva não apenas revelar de que maneira esse fenômeno se constitui em estratégia de argumentatividade nos gêneros descritos, mas também observar quais os efeitos de sentido que são gerados nos enunciados e textos em que aparece esse fenômeno.

Trata-se, na verdade, da apresentação ${ }^{1}$ dos resultados de investigações científicas que foram desenvolvidas em dois laboratórios da Universidade Federal da Paraíba (o LAEL - Laboratório de Estudos Linguísticos e o LASPRAT - Laboratório SemânticoPragmático de Textos), sob nossa orientação, que descreveram a modalização, entre outras estratégias semântico-argumentativas e pragmáticas, em gêneros acadêmicos. As investigações aqui referidas filiam-se ao Projeto ESAGD (Estudos Semânticos Argumentativos de Gêneros do Discurso: gêneros acadêmicos e formulaicos) e, mais recentemente, ao Projeto ESAELD (Estudos Semântico-Argumentativos e Enunciativos na Língua e no Discurso: marcas de (inter)subjetividade e de orientação argumentativa.

No que se refere, especificamente, à modalização discursiva, as investigações foram fundamentadas nos estudos de diferentes estudiosos, em especial Lyons (1977), Cervoni (1989), Castilho e Castilho (1993), Koch (2012), Nascimento (2009, 2010) e Nascimento e Silva (2012). Convém ressaltar, no entanto, que consideramos a modalização como um fenômeno que permite ao locutor deixar registrado, no seu discurso, marcas de sua subjetividade através de determinados elementos linguísticos e, portanto, imprimir um modo como esse discurso deve ser lido, funcionando, assim, como uma estratégia semântico-argumentativa e pragmática, na perspectiva de Nascimento (2010).

Como se adota, neste trabalho, a modalização sob o ponto de vista semântico-argumentativo e pragmático, a argumentação é aqui vista como um fenômeno linguístico-discursivo, na perspectiva de Ducrot $(1987,1988)$ e colaboradores. A língua é fundamentalmente argumentativa, afirma o estudioso, e vai da língua ao discurso, permitindo determinadas orientações e conclusões. Assim, não só a língua, mas também o uso que dela fazemos é argumentativo, como acrescenta Espíndola (2004).

\footnotetext{
${ }^{1}$ Ressaltamos que parte dos resultados aqui relatados foram apresentados no I Seminário do Grupo de Pesquisa Conectivo e Conexões de Orações, realizado na Universidade Federal Fluminense, em Niterói-RJ, no período de 8 a 10 de novembro de 2016. Naquela ocasião, foram relatados dados parciais. Aqui apresentamos os resultados finais das investigações, com dados já consolidados.
} 
As investigações desenvolvidas pelos projetos ESAGD, no período de 2009 a 2016, e ESAELD², a partir de 2017, são de natureza qualitativa e de caráter descritivo e interpretativista. Apesar das investigações serem de natureza qualitativa, observamos quais modalizadores ocorriam com mais frequência em determinados gêneros, a fim de verificar que tipos de modalização são mais comuns nos gêneros do universo acadêmico. No período acima assinado, foi descrita a modalização, entre outras estratégias argumentativas, em diferentes gêneros discursivos. Do universo acadêmico, os gêneros descritos foram o resumo, a resenha, o projeto de pesquisa de TCC, a monografia de TCC e o artigo científico, em língua portuguesa, e a ata administrativo-acadêmica, em língua espanhola. Ressaltamos que, embora em língua espanhola, a ata-administrativa acadêmica foi incluída em razão de os fenômenos investigados serem os mesmos e não observarmos nenhuma diferença significativa na funcionalidade dos modalizadores de um idioma para o outro, no que se refere ao aspecto semântico-argumentativo. Além disso, a utilização de corpora dos dois idiomas nos permitiu observar com mais propriedade o fenômeno da modalização. É importante considerar ainda que, embora não seja um gênero que descreva ou relate o fazer científico ou acadêmico, a ata administrativo-acadêmica nele interfere e também reflete sua voz, uma vez que relata as ações e decisões dos conselhos acadêmicos.

Os procedimentos adotados, durante as investigações, foram os seguintes:

a) leitura e discussão a respeito da Teoria da Argumentação na Língua, dos Estudos sobre a Modalização e sobre o gênero a ser descrito;

b) coleta, armazenamento e seleção dos textos a serem investigados;

c) levantamento das estruturas semântico-argumentativas presentes nos textos;

d) descrição e análise das estruturas semântico-argumentativas presentes nos textos;

e) reflexão teórica a partir da descrição e da análise dos dados obtidos e sistematização dos resultados.

Os corpora que compõem os projetos ESAGD e ESAELD foram coletados em diferentes instituições de ensino superior e de pesquisa públicas e privadas, no Brasil e no exterior, em diferentes bancos de dados. A seleção dos textos se deu sempre considerando a presença do fenômeno investigado no gênero, bem como a representatividade da amostra. No entanto, como a investigação é, principalmente, de natureza qualitativa, dado o objetivo de descrever e analisar o funcionamento da modalização, entre outros fenômenos, como elemento que imprime argumentatividade nos textos, não nos pautamos por critérios quantitativos dessa ocorrência, mas pela própria natureza do fenômeno e seu funcionamento.

Ressaltamos que a análise realizada foi de caráter qualitativo, no entanto, em alguns gêneros foi possível quantificar a ocorrência dos modalizadores, a fim de verificar não só qual modalização se sobressaía em cada gênero, mas também realizar comparações entre os gêneros descritos, muitas das quais relatamos neste trabalho.

Foram envolvidos na investigação desses gêneros, além do coordenador do projeto, o autor deste artigo, 03 alunos de doutorado, 01 aluna do mestrado em Linguística do Proling/UFPB ${ }^{3}$ e 01 aluno (bolsista de Iniciação Científica) da graduação em Secretariado

\footnotetext{
${ }^{2} \mathrm{O}$ projeto ESAELD dá continuidade às investigações desenvolvidas pelo projeto ESAGD, ampliando o escopo dos gêneros e dos fenômenos investigados. No projeto ESAGD foram investigados o resumo, a resenha, o artigo científico, a ata administrativo-acadêmica e o projeto de pesquisa de TCC, no que se refere aos gêneros acadêmicos. A monografia de TCC foi investigada no âmbito do projeto ESAELD. Ambos os projetos possuem o mesmo objetivo de pesquisa, qual seja: descrever e analisar o funcionamento de diferentes estruturas e fenômenos semântico-argumentativos e enunciativos, a partir de diferentes gêneros discursivos e em diferentes contextos de uso da língua, bem como adotam os mesmos procedimentos metodológicos.

${ }^{3}$ Coordenador do projeto: Erivaldo Pereira do Nascimento, com o gênero ata administrativo-acadêmica (NASCIMENTO, 2014). Doutorandos: Clécida Maria de Bezerra Bessa, com o artigo científico (BESSA, 2015); Maria Vanice de Lacerda de Melo Barbosa, com a resenha (BARBOSA, 2015); Ana Carolina de Vieira Bastos, com a monografia de TCC (BASTOS, 2017). Mestranda: Aleise Guimarães Carvalho, com o gênero projeto de pesquisa de TCC (CARVALHO, 2014).
} 
Executivo Bilíngue, também da UFPB ${ }^{4}$. Cada um dos pesquisadores trabalhou com um gênero específico e as investigações se deram sob nossa orientação e supervisão.

Assim, este artigo reúne resultados de pesquisas realizadas em três teses de doutorado, uma dissertação de mestrado e dois relatórios de pesquisa, todas inter-relacionadas entre si, uma vez que objetivaram descrever e analisar a argumentação em gêneros acadêmicos, mapeando, entre outros fenômenos, a modalização discursiva ${ }^{5}$. Embora cada uma dessas pesquisas trate da argumentação em um gênero específico, elas contribuem para uma finalidade maior dos projetos ESAGD e ESAELD, que é descrever o fenômeno da argumentatividade linguística. É nesse sentido que este trabalho correlaciona os resultados obtidos nessas pesquisas, no que se refere especificamente à modalização, procurando refletir sobre a presença desse fenômeno no universo acadêmico, ou seja, na linguagem da academia e da ciência.

Para tal, organizamos o artigo em três partes, além desta seção introdutória. Inicialmente, tratamos do fenômeno da modalização como uma estratégia semântico-argumentativa. Apresentamos, ainda, a classificação dos elementos modalizadores que adotamos nas investigações dos projetos ESAGD e ESAELD. Na segunda seção, trazemos as reflexões a respeito do fenômeno da modalização nos gêneros acadêmicos, a partir das investigações realizadas pelo referido projeto. Para tal, utilizaremos recortes dos trabalhos (teses, dissertações e relatórios) que resultaram das pesquisas. Na última seção, das considerações finais, sumarizamos os resultados obtidos, refletindo sobre a importância dos estudos da modalização para a análise e descrição dos gêneros acadêmicos.

\section{A MODALIZAÇÃO COMO ESTRATÉGIA SEMÂNTICO-ARGUMENTATIVA}

O fenômeno da modalização, ou modalidade, tem sido objeto de estudo de diferentes áreas e correntes dos estudos linguísticos. No entanto, os primeiros estudos sobre a modalidade nasceram na lógica.

Lyons (1977, p. 329) afirma que, na lógica tradicional, o termo modalidade é utilizado para descrever a quantificação do predicado: "Na lógica tradicional (baseada na análise bipartida entre sujeito e predicado), a modalidade foi comumente descrita como quantificação do predicado" (tradução nossa) ${ }^{6}$.

No entanto, Lyons (1977) aponta que, tanto na linguística como na lógica, o termo tem provocado uma série de interpretações conflitantes, devido a sua aproximação com os termos modo e modal. O autor reconhece que há uma aproximação etimológica óbvia entre esses três termos, mas acrescenta que prefere reservar o termo modo para o sentido que lhe atribui a Gramática Tradicional, para se referir às categorias gramaticais denominadas de indicativo, subjuntivo e imperativo.

Lyons (1977) ainda acrescenta que o único tipo de modalidade reconhecido pela lógica tradicional é o que relaciona as noções de necessidade e possibilidade ao valor de verdade e falsidade das proposições, ou seja, a modalidade alética. Os lógicos relacionam a modalidade alética, segundo Lyons (1977), mais à necessidade do que à possibilidade. Necessidade é definida em termos de verdade em todos os universos possíveis, e possibilidade em termos de verdade em alguns universos possíveis.

\footnotetext{
${ }^{4}$ Geziel de Brito Lima, em conjunto com o coordenador do projeto, com o gênero resumo acadêmico (LIMA; NASCIMENTO, 2009).

${ }^{5}$ É importante mencionar que outros fenômenos também foram investigados nesses corpora, tais como a polifonia enunciativa. A esse respeito, pode ser consultado o trabalho A polifonia dos gêneros acadêmicos e formulaicos: a evocação da palavra alheia, de Nascimento (2015). Neste artigo, no entanto, o foco será especificamente o fenômeno da modalização.

${ }^{6}$ No original: "In traditional logic (based on a bipartite analysis of propositions into subject and predicate), modality was commonly described as quantification of the predicate" (LYONS, 1977, p. 329).
} 
Cervoni (1989) afirma que o termo modalidade implica a ideia de que uma análise semântica permite distinguir, em um enunciado, um conteúdo proposicional (dito) de um ponto de vista do falante sobre esse conteúdo (modalidade). Para o autor, a modalidade é constitutiva da significação fundamental do enunciado, o que a distingue da conotação.

Para Cervoni (1989), o fenômeno da modalidade na Linguística, embora tenha suas raízes na lógica e conserve alguma coisa de sua significação original, deve ser tratado com a máxima atenção à morfologia, à sintaxe e ao léxico. Por essa razão, ele retoma a noção tradicional de que só ocorre modalidade quando essa incide sobre a proposição como um todo, para afirmar que, nas teorias linguísticas contemporâneas, a partir da análise das formas de superfície e do implícito, discute-se a modalidade incidindo sobre parte da proposição, o sintagma nominal, por exemplo. Acrescenta o autor:

Conforme a definição tradicional, só serão consideradas modalidades as determinações referentes a uma proposição. Mas, para o linguista, não há hipótese de ver proposições apenas nas frases que têm uma forma canônica (Sócrates corre, educa os jovens, é um homem...). As teorias linguísticas contemporâneas demonstraram a vantagem de se supor estruturas subjacentes para as formas de superfície e de dar lugar ao implícito na análise das frases (CERVONI, 1989, p. 62, grifos do autor).

Por essa razão, esse autor apresenta uma classificação segundo a qual se pode distinguir o que é tipicamente modal do que é parcialmente modal e do que é possível e vantajoso excluir do campo das modalidades. O que é tipicamente modal, ele denominou de núcleo duro, o que é parcialmente modal foi denominado de modalidade impura.

Dentro do núcleo duro foram incluídas as modalidades proposicionais, em frases do tipo "(unipessoal) + é + Adjetivo + que P ou Infinitivo", e os auxiliares de modo, uma vez que ambos, para Cervoni (1989, p. 63), "[...] têm uma significação essencialmente modal perfeitamente explícita”.

Com relação à modalidade impura, o autor afirma que essa inclui "[...] os casos em que a modalidade é implícita ou mesclada num lexema, num mesmo morfema, numa mesma expressão, a outros elementos da significação" (CERVONI, 1989, p. 68). Nesse grupo, estão incluídos alguns adjetivos avaliativos, como útil, agradável, interessante, grave etc., os verbos dicendi e os modos verbais. No entanto, ao tratar dos adjetivos avaliativos, Cervoni (1989) afirma que esses só serão modais quando for possível recuperar a forma canônica.

Castilho e Castilho (1993, p. 217) afirmam que o termo modalização expressa um julgamento do falante perante a proposição; no entanto, dois termos têm sido empregados nesse sentido: modalidade e modalização - o primeiro quando "[...] o falante apresenta o conteúdo proposicional numa forma assertiva (afirmativa ou negativa), interrogativa (polar ou não polar) e jussiva (imperativa ou optativa)". O termo modalização tem sido usado quando "[...] o falante expressa seu relacionamento com o conteúdo proposicional" (CASTILHO; CASTILHO, 1993, p. 217). Esse relacionamento consiste em julgar o teor de verdade da proposição, ou expressar um julgamento sobre a forma escolhida para verbalizar o conteúdo da proposição.

No entanto, esses autores preferem usar os termos indistintamente, pois “[...] há sempre uma avaliação prévia do falante sobre o conteúdo da proposição que ele vai veicular” (CASTILHO; CASTILHO, 1993, p. 217). Eles acrescentam que decorrem daí as decisões do falante sobre afirmar, negar, interrogar, expressar dúvida, certeza etc.

A partir de Dubois (1973), Santos (2000) afirma que a modalização é uma categoria que permite ao falante expressar uma atitude em face do enunciado que produz. A modalidade, por sua vez, é sinônima de modo e indica o tipo de comunicação instituído pelo falante entre ele e o seu interlocutor.

Analisando os autores supramencionados, temos observado que a modalização tem sido vista, geralmente, como uma estratégia inerente ao enunciado, recaindo ora sobre o enunciado como um todo, ora sobre parte deste. Percebemos, ainda, que a distinção entre o que é modalização e o que é modalidade não é um problema resolvido. A não resolução desse problema tem sua base na distinção entre subjetividade e intersubjetividade, como também no fato de considerar que é possível separar o subjetivo do 
intersubjetivo (NASCIMENTO, 2010). No processo de interação, esses fenômenos não são tão separáveis assim, tampouco na própria estrutura da língua, como afirma Ducrot (1988).

Assim, ao asseverar um enunciado do tipo "É certo que Pedro venha", o locutor, além de expressar certeza com relação ao fato da vinda futura de Pedro, o faz em função do seu interlocutor, ou porque queira que seu interlocutor acredite também que essa informação é verdadeira, ou porque tem outra intenção, que, algumas vezes, só é recuperada pela enunciação. Nesse sentido, não nos parece produtivo separar a atitude do falante (expressar certeza, logo, modalização) da sua intenção (fazer com que o interlocutor acredite que isso é uma verdade, logo, modalidade). Tampouco parece produtivo, do ponto de vista semânticoargumentativo, separar a escolha em asseverar (expressar uma certeza = modalização) do julgamento feito pelo falante (eu considero isso uma verdade $=$ modalidade). Esses fenômenos não estão separados, como observaram Castilho e Castilho (1993), e constituemse em uma estratégia de argumentação. Isso já pudemos constatar nos estudos sobre a modalização em vários gêneros textuais/discursivos (NASCIMENTO, 2009, 2010).

As nossas investigações nos fizeram perceber que há sempre uma avaliação do locutor (modalidade) em função da interlocução, no sentido de expressar suas intenções (modalização) e, por essa razão, não parece produtivo separar aspectos subjetivos de intersubjetivos, pois esses estão intrinsecamente relacionados (um só se manifesta em função do outro). Assim, reiteramos: "Logo também não se é produtivo, a priori, separar modalidade de modalização, pelo menos quando formos tratar esse fenômeno como uma estratégia argumentativa” (NASCIMENTO, 2009, p. 1376). Tal posicionamento se baseia, como já foi assinalado, em Ducrot (1988), que reúne os aspectos subjetivos e intersubjetivos dos enunciados em um único aspecto, por ele denominado de valor argumentativo dos enunciados.

O valor argumentativo se constitui, conforme postula Ducrot (1988), no sentido do enunciado, que é ao mesmo tempo significação e direção (orientação discursiva). Assim, a presença de um determinado elemento linguístico modalizador, por exemplo, não só porta uma determinada significação (certeza, possibilidade, obrigação etc.), como permite uma determinada continuação discursiva, uma determinada orientação, apontando para determinadas conclusões e produzindo determinados efeitos de sentido (comprometimento, distanciamento, avaliação axiológica etc). Dessa forma, a modalização constitui-se em um índice de argumentação.

Segundo Lyons (1977), todas as línguas naturais proveem seus falantes com recursos prosódicos (acentuação e entonação) com os quais eles expressam tipos distintos de enunciados epistêmicos. Alguns, mas nem todos, são gramaticalizados (categoria de modo), alguns são lexicalizados ou semilexicalizados (verbos modais - dever; adjetivos modais - possível; advérbios modais possivelmente; partículas modais - talvez).

Castilho e Castilho (1993) também afirmam que a modalização movimenta diferentes recursos linguísticos, entre os quais citam a prosódia, os modos verbais, os verbos auxiliares como dever e querer, os verbos que constituem orações parentéticas e matrizes como achar, crer e acreditar, os adjetivos, os advérbios, os sintagmas preposicionados com função adverbial, entre outros. Da mesma forma como a modalização pode se lexicalizar de diversas maneiras, diferentes tipos de modalidade podem ser veiculados com um mesmo item lexical, segundo Koch (2002). Este é o caso do verbo dever, que pode veicular possibilidade, probabilidade, dúvida, certeza etc.

Koch (2002) ainda apresenta uma lista de vários tipos de lexicalização das modalidades, entre os quais estão os performativos explícitos: eu ordeno, eu proíbo, eu permito etc.; os auxiliares modais: poder, dever, querer, precisar etc.; os predicados cristalizados: é certo, é preciso, é necessário, é provável etc.; os advérbios modalizadores: provavelmente, certamente, necessariamente, possivelmente etc.; as formas verbais perifrásticas: dever, poder, querer etc. + infinitivo; os modos e tempos verbais: imperativo; certos empregos de subjuntivo; o uso do pretérito perfeito com valor de probabilidade, hipótese, notícia não confirmada; o uso do imperfeito do indicativo com valor de irrealidade etc.; os verbos de atitude proposicional: eu creio, eu sei, eu duvido, eu acho etc.; o fenômeno da entonação (que permite, por exemplo, distinguir uma ordem de um pedido na linguagem oral); e os operadores argumentativos: pouco, um pouco, quase, apenas, mesmo etc. 
Essa listagem, no entanto, não é finita, pois a cada ano as investigações têm apontado outros elementos da língua com função modalizadora, entre os quais temos o caso do sufixo -inho (investigado por Chaves, 2007), dos verbos dicendi (investigado por Nascimento, 2005) e da repetição (investigada por Adelino, 2016).

Os modalizadores, elementos linguísticos que materializam, explicitamente, a modalização, costumam ser classificados de acordo com o tipo de modalização que expressam, nos enunciados e discursos em que aparecem. No entanto, diferentes estudiosos têm apresentado diferentes classificações para os tipos e subtipos de modalização. Neste trabalho, adotamos a classificação de Nascimento e Silva (2012), que agruparam os elementos modalizadores em quatro grandes grupos, a partir das investigações realizadas pelo projeto ESAGD, considerando os efeitos de sentido que geram nos enunciados ou na enunciação propriamente dita: epistêmicos, deônticos, avaliativos e delimitadores. O quadro a seguir, dos referidos autores, sumariza os tipos de modalização.

\begin{tabular}{|c|c|c|}
\hline Tipo de Modalização & Subtipos & Efeito de sentido no enunciado ou enunciação \\
\hline \multirow{3}{*}{$\begin{array}{l}\text { Epistêmica - expressa avaliação } \\
\text { sobre o caráter de verdade ou } \\
\text { conhecimento }\end{array}$} & Asseverativa & Apresenta o conteúdo como algo certo ou verdadeiro. \\
\hline & Quase-asseverativa & $\begin{array}{c}\text { Apresenta o conteúdo como algo quase certo ou } \\
\text { verdadeiro. }\end{array}$ \\
\hline & Habilitativa & $\begin{array}{l}\text { Expressa a capacidade de algo ou alguém realizar o } \\
\text { conteúdo do enunciado. }\end{array}$ \\
\hline \multirow{4}{*}{$\begin{array}{c}\text { Deôntica - expressa avaliação } \\
\text { sobre o caráter facultativo, } \\
\text { proibitivo, volitivo ou de } \\
\text { obrigatoriedade }\end{array}$} & De obrigatoriedade & $\begin{array}{c}\text { Apresenta o conteúdo como algo obrigatório e que } \\
\text { precisa acontecer. }\end{array}$ \\
\hline & De proibição & $\begin{array}{l}\text { Expressa o conteúdo como algo proibido, que não pode } \\
\text { acontecer. }\end{array}$ \\
\hline & De possibilidade & $\begin{array}{l}\text { Expressa o conteúdo como algo facultativo ou dá a } \\
\text { permissão para que algo aconteça. }\end{array}$ \\
\hline & Volitiva & Expressa um desejo ou vontade de que algo ocorra. \\
\hline $\begin{array}{l}\text { Avaliativa - expressa avaliação ou } \\
\text { ponto de vista }\end{array}$ & --- & $\begin{array}{c}\text { Expressa uma avaliação ou ponto de vista sobre o } \\
\text { conteúdo, excetuando-se qualquer caráter deôntico ou } \\
\text { epistêmico. }\end{array}$ \\
\hline Delimitadora & --- & $\begin{array}{c}\text { Determina os limites sobre os quais se deve considerar o } \\
\text { conteúdo do enunciado. }\end{array}$ \\
\hline
\end{tabular}

Quadro 1: Tipos e subtipos de modalização

Fonte: Nascimento e Silva (2012, p. 93)

Convém ainda ressaltar que um mesmo item lexical pode expressar diferentes modalidades, gerando efeitos de sentido diferentes. Obviamente que, para determinar o tipo de modalidade expressa, é necessária uma análise semântico-discursiva do item em questão, conforme Nascimento e Silva (2012).

\section{A MODALIZAÇÃO NOS GÊNEROS ACADÊMICOS}

Nas investigações realizadas pelos projetos ESAGD e ESAELD sobre a argumentatividade nos gêneros acadêmicos, mapeamos todos os tipos (com alguns de seus subtipos) de modalizadores discursivos, apresentados por Nascimento e Silva (2012). Embora não tenha sido possível quantificar a ocorrência de todos os tipos e subtipos em todos os gêneros, observamos que, em geral, prevalecem os modalizadores epistêmicos asseverativos e quase-asseverativos e os modalizadores avaliativos, em todos os gêneros 
do universo acadêmico que foram pesquisados. Os modalizadores deônticos e os delimitadores não são muito significativos nos corpora analisados, embora presentes em alguns gêneros, como o resumo acadêmico e a ata administrativo-acadêmica.

Apresentamos, a seguir, a análise descritivo-interpretativa de alguns trechos dos corpora descritos, a fim de demonstrar não só a ocorrência desses modalizadores presentes nos gêneros, mas, sobretudo, os efeitos de sentido que geram nos enunciados em que aparecem.

\subsection{MODALIZADORES EPISTÊMICOS ASSEVERATIVOS}

A modalização epistêmica asseverativa ocorre, conforme Nascimento e Silva (2012), quando o conteúdo do enunciado (ou a própria enunciação) é apresentado como algo certo ou verdadeiro e, por esse motivo, o locutor responsável pelo discurso compromete-se com o dito do enunciado. Nesse sentido, o locutor apresenta um alto grau de adesão com relação ao conteúdo do enunciado, como afirma Castilho e Castilho (1993).

Os modalizadores epistêmicos asseverativos foram encontrados em todos os gêneros descritos (resumo, resenha, artigo, projeto de pesquisa de TCC, monografia de TCC e ata administrativo-acadêmica). A sua ocorrência se deu, no gênero resumo, principalmente através de verbos e advérbios modais, ou ainda através de verbos dicendi modalizadores nos demais gêneros. Os trechos 01 e 02 , a seguir, ilustram essa ocorrência.

\section{TRECHO 01 - Resumo (LIMA; NASCIMENTO, 2009)}

$\mathrm{Na}$ investigação constatou-se que seleção lexical está diretamente relacionada à classe socioeconômica do destinatário e reflete-lhe os anseios, o estilo de vida e os valores ideologicamente consagrados pela classe social a que ele pertence.

No trecho 01, do corpus descrito por Lima e Nascimento (2009), observa-se a presença da modalização epistêmica asseverativa através do modalizador "constatou-se que", cujo efeito de sentido recai sobre o conteúdo de todo o enunciado, apresentando-o como algo constatado, logo, provado, e, por isso mesmo, certo ou verdadeiro. Se considerarmos que o texto científico deve ser baseado em experimentos, dados ou fenômenos comprovados e testados, logo, provados, justifica-se não só o uso dessa expressão, como também o efeito de sentido que ela gera no enunciado, o efeito de asseveração. Por esse motivo, é possível considerar o modalizador em destaque como epistêmico asseverativo.

No corpus analisado, Lima e Nascimento (2009) mapearam dezoito ocorrências de modalizadores epistêmicos asseverativos e verificaram que esse tipo de modalização foi utilizado, sobretudo, para apresentar dados e resultados de investigações, como algo comprovado, logo, digno de certeza. Além disso, foi utilizado para apresentar informações compartilhadas no universo acadêmico, de conhecimento do locutor e de seus prováveis interlocutores, e tidas como certas, em enunciados do tipo "É notório o avanço da tecnologia em nossa sociedade". O trecho que segue, retirado do corpus analisado por Carvalho (2014), ilustra outra ocorrência da modalização epistêmica asseverativa presente nos corpora descritos.

\section{TRECHO 02 - Projeto de Pesquisa de TCC (CARVALHO, 2014)}

A respeito dessas transformações, Marcuschi (2012, p. 36) afirma que há dois momentos significativos no contexto sócio-histórico do LD "o marco inicial está diretamente relacionado à época em que os livros de uso no espaço escolar começam a ser nomeados como livros didáticos (...)" e o segundo marco provém da preocupação de se "compreender o momento atual vivenciado pelas coleções didáticas no contexto social brasileiro", pois a concepção de língua no LDPB sofreu alterações no transcorrer das últimas oito décadas.

O trecho 02 ilustra a ocorrência da modalização discursiva não só no gênero investigado por Carvalho (2014), mas também nos demais gêneros analisados pelo Projeto ESAGD, em que esse fenômeno se dá em conjunto com a polifonia de locutores e através de verbos dicendi modalizadores. Os verbos dicendi modalizadores, conforme Nascimento (2005), são utilizados pelo locutor responsável pelo discurso (L1) para introduzir o relato de outros locutores (L2, L3 etc.) em seu enunciado e, ao mesmo tempo, apresentar o conteúdo do relato como algo certo ou verdadeiro, comprometendo-se, assim, o dito alheio. 
Analisando o trecho 02, Carvalho $(2014)^{7}$ observa a presença de dois locutores distintos: L1 apresenta o conteúdo do enunciado e, pretendendo que essa afirmação se torne válida em termos acadêmicos, insere a voz de outro locutor, L2: Marcuschi. Para introduzir a voz de L2, L1 utiliza o verbo dicendi modalizador asseverativo afirmar, portador da síntese lexêmica dizer + certeza (dizer com certeza), nos termos utilizados por Cervoni (1989). Ao apresentar o relato de L2 como algo certo ou verdadeiro, L1 não só indica como esse discurso deve ser lido, como também se engaja e admite o discurso de L2, constituído discursivamente como uma autoridade no assunto, um arrazoado por autoridade, nos termos de Ducrot (1987). O relato de L2 é incorporado ao discurso de L1, que o admite como certo e a partir do qual dá continuidade ao seu dizer.

Esse tipo de estratégia, presente em todos os gêneros investigados, ilustra um dos principais usos dos modalizadores epistêmicos asseverativos nos gêneros do universo acadêmico: imprimir uma análise do discurso alheio, permitindo o engajamento do locutor responsável pelo dito com as vozes do outro. Esse tipo de estratégia não só gera o efeito de credibilidade ao que foi enunciado, como também permite que L1 se valha do dizer alheio para fundamentar suas investigações, suas comprovações e seus resultados, ou seja, o seu fazer acadêmico. Assim, os efeitos de sentido gerados nos enunciados são: certeza, credibilidade e assimilação ou engajamento.

\subsection{MODALIZADORES EPISTEMMICOS QUASE-ASSEVERATIVOS}

A modalização epistêmica quase-asseverativa ocorre quando o falante considera o conteúdo do enunciado ou discurso quase certo ou como uma hipótese a ser confirmada e, por isso, não se responsabiliza pelo valor de certeza ou verdade do enunciado, nem se compromete com a veracidade do que afirma, conforme assinalam Nascimento e Silva (2012).

Em todos os corpora analisados, foram identificados modalizadores epistêmicos quase-asseverativos, com relativa frequência e imprimindo diferentes efeitos de sentido, conforme demonstram os trechos 03 e 04 abaixo analisados.

TRECHO 03 - Resumo (LIMA; NASCIMENTO, 2009)

Esse aumento na demanda de estudantes de E/LE se deve, provavelmente, às relações do Brasil com o MERCOSUL.

No trecho 03, retirado de um resumo acadêmico publicado em anais de um evento científico, observa-se que o locutor responsável pelo discurso apresenta o conteúdo do dito como algo provável de ocorrer, como uma hipótese que necessita de confirmação. Esse caráter de possibilidade ou probabilidade é expresso no conteúdo do enunciado pela presença do modalizador epistêmico quaseasseverativo "provavelmente". Ao utilizar esse modalizador, o locutor não se compromete com o conteúdo do dito (Esse aumento na demanda de estudantes de E/LE se deve às relações do Brasil com o MERCOSUL), isentando-se de responsabilidade com relação à certeza ou à verdade do que foi enunciado.

No corpus analisado por Lima e Nascimento (2009), foram mapeados 52 modalizadores epistêmicos quase-asseverativos, em quantidade superior inclusive aos asseverativos (dezoito ocorrências), sempre indicando um não comprometimento com relação ao dito. Segundo os pesquisadores, essa ocorrência se deu, sobretudo, em resumos sobre pesquisas que ainda estavam em fase de desenvolvimento, ou seja, os autores ainda não haviam chegado aos resultados finais e, consequentemente, também não poderiam se comprometer com relação ao que estavam enunciando: "Por esta razão é que podemos perceber com frequência a presença de expressões como 'buscamos descobrir', 'pretendemos discutir', 'pretendemos revelar', entre outras, que deixam claro que a pesquisa está em fase de desenvolvimento" (LIMA; NASCIMENTO, 2009, p. 8). Os autores ainda mapearam modalizadores epistêmicos quase-asseverativos em enunciados que tratavam de questões polêmicas do ponto de vista científico, ou que apresentavam hipóteses a serem confirmadas, sempre isentando o locutor com relação ao dito.

\footnotetext{
${ }^{7}$ No corpus investigado por Carvalho (2014) foram mapeadas 55 ocorrências de modalizadores epistêmico-asseverativos, todos sob a forma de verbos dicendi modalizadores e em enunciados com arrazoado por autoridade. O arrazoado por autoridade, conforme Ducrot (1987), existe em situações em que um locutor, ao introduzir a voz de um segundo locutor em seu discurso, a apresenta como uma autoridade no assunto que fundamenta o seu dizer.
} 
TRECHO 04 - Resenha (BARBOSA, 2015)

A traição, como já ficara sugerido décadas atrás na peça de Chico Buarque e Rui Guerra sobre Calabar, não pode ser vista sob a perspectiva meramente moral, que tendemos a lhe imputar. Muitos outros contemporâneos desse homem "alto, magro, preto, e feio", traíram. Uns, como João Fernandes Vieira, grande herói do panteão pernambucano, se deram bem. Manoel se deu mal, talvez porque, além de traidor, foi herege. As peripécias e indecisões desse mestiço cabotino e inteligentíssimo parecem metáfora do que era a colonização no século 17, quando a política europeia se redefinia com as tintas de outros mundos, das Américas, da Índia, da África, da China, e quando o poderio marítimo ibérico minguava mais e mais ante a pujança holandesa, antes que a Inglaterra entrasse de vez em cena, e para acabar com a festa. (R3)

Ao analisar o trecho 04, retirado de uma resenha acadêmica, Barbosa (2015) identifica uma polifonia de locutores. Para analisar a obra do autor resenhado, o locutor resenhista (L1) introduz, em estilo indireto, o discurso de um segundo locutor (L2 - a peça de Chico Buarque e Rui Guerra), segundo o qual a traição não pode ser vista sob a perspectiva meramente moral. Esse relato é introduzido pela expressão "como já ficara sugerido". Segundo Barbosa (2015), o verbo dicendi "sugerir" é modalizador quaseasseverativo, visto expressar algo considerado possível: "No contexto em que foi usado, indica a forma como o discurso de L2 deve ser lido: como uma sugestão" (BARBOSA, 2015, p. 131).

No entanto, a pesquisadora observa que, embora o discurso de L2 seja apresentado como algo possível de ser certo (sugerido), L1 o assimila, o que decorre da utilização dos operadores argumentativos "como" e "já".

Assim, o fato de apresentar o relato como algo possível de ser certo não implicou em um distanciamento do discurso de L2, por parte de L1, mas apenas no julgamento do discurso alheio como algo possivelmente certo ou verdadeiro, embora admissível. Isso significa que a modalização epistêmica quase-asseverativa, ao apresentar o discurso como possivelmente certo ou verdadeiro, também pode ter seu efeito de não comprometimento ou distanciamento anulado, dependendo do contexto discursivo em que ocorra.

Assim, os efeitos de sentido mapeados pelo uso dos modalizadores epistêmicos quase-asseverativos nos corpora investigados foram: noção de possibilidade ou probabilidade, não comprometimento, distanciamento, não engajamento.

\subsection{MODALIZADORES DEÔNTICOS}

A modalização deôntica está relaciona ao caráter instrucional ou de orientação da linguagem e, nesse sentido, pode implicar obrigatoriedade, permissão, volição e proibição, conforme postulam Nascimento e Silva (2012).

Nos corpora analisados, a sua ocorrência é muito baixa, tendo sido registrada em apenas dois gêneros:

a) no gênero resumo, com ocorrência de modalizadores deônticos de obrigatoriedade, indicando, muito mais do que uma instrução, um posicionamento subjetivo e de caráter axiológico do locutor responsável pelo resumo com relação ao conteúdo do dito, em enunciados tais como "Sendo assim os cuidados com as influências trazidas por essa tecnologias devem ser redobradas" (LIMA; NASCIMENTO, 2009);

b) no gênero ata administrativo-acadêmica, em língua espanhola, indicando ora obrigatoriedade, ora volição, como no trecho que segue:

\footnotetext{
${ }^{8}$ Barbosa (2015) assinala que o elemento linguístico "como", junto aos verbos do dizer, normalmente indica conformidade com o ponto de vista introduzido, o que se observa no exemplo analisado. No que se refere ao operador "já”, esse indica, no contexto em que foi usado, uma ação consumada, ou seja, indica algo já dito, fato consumado e, por isso, possível de ser admitido. Nesse sentido, afirma que “[...] o verbo dicendi e os recursos linguísticos 'como’ e ‘já’ possibilitam verificar que L1 assimila o dito de L2, apresentado em relato em estilo indireto" (BARBOSA, 2015, p. 131).
} 
TRECHO 05 - ata administrativo-acadêmica (NASCIMENTO, 2014)

Solicitud aula Dra. Pizarro: se acuerda otorgar el aula siempre que no perjudique el dictado de

alguna materia del Departamento. Se requerirá que dicha solicitud sea refrendada por el Departamento en el cual ejercen los docentes.

No trecho 05, do gênero ata administrativo-acadêmica, em língua espanhola, identifica-se a voz de um SE-locutor, que se refere à voz coletiva de um conselho departamental", introduzido pelas formas verbais "se acuerda" e "se requerirá". O enunciado se refere a uma solicitação para utilização de uma sala de aula pela Dra Pizarro a um conselho acadêmico que decidiu autorizar a cessão da sala, desde que não se prejudicasse a utilização por docentes do Departamento. Com a forma verbal dicendi "se requerirá” é colocado em cena o ponto de vista do SE-locutor, como uma solicitação ou vontade do próprio conselho, de caráter deôntico: com essa expressão verbal, o locutor responsável pelo discurso como um todo (aquele que assina a ata) apresenta o ponto de vista do SElocutor (a solicitação seja referendada pelo Departamento ao qual se vinculam os professores que usam a sala) como uma solicitação que deverá ser realizada; indicando, consequentemente, como esse ponto de vista deve ser lido. Por esse motivo, a expressão dicendi "se requerirá" constitui-se em um modalizador deôntico volitivo ${ }^{10}$, já que, através dele, o locutor responsável pela ata apresenta o discurso do SE-locutor como um desejo ou vontade, de caráter deôntico.

A baixa ocorrência dos modalizadores deônticos nos textos do domínio acadêmico é perfeitamente justificável se considerarmos que esse universo de atividade humana não tem, a priori, a função de normatizar ações e fatos sociais, mas principalmente de descrevê-los e explicá-los, à luz do conhecimento científico. Talvez por esse motivo a sua ocorrência se fez notar exatamente no gênero ata administrativo-acadêmica que, mesmo sendo produzida e circulando na academia, está muito mais relacionada ao setor administrativo, em específico aos conselhos e órgãos colegiados, registrando decisões e instruções, quer de natureza acadêmicopedagógica, quer de natureza puramente administrativa.

\subsection{MODALIZADORES AVALIATIVOS}

A modalização avaliativa, segundo Nascimento e Silva (2012), imprime um juízo de valor do locutor responsável pelo discurso a respeito do conteúdo do enunciado, excetuando-se qualquer avaliação de caráter deôntico ou epistêmico. Em todos os gêneros investigados foram catalogados modalizadores avaliativos, com uma frequência bastante significativa: nos gêneros projeto de pesquisa de TCC, resumo e ata administrativo-acadêmica, por exemplo, foram os modalizadores com a segunda maior ocorrência.

Nos corpora investigados, os modalizadores avaliativos foram empregados pelo locutor responsável pelo discurso de duas maneiras:

a) avaliando o seu próprio dizer, imprimindo um juízo de valor sobre o conteúdo do seu próprio dito, em enunciados do tipo "Felizmente os estudos direcionados aos gêneros textuais a cada dia que passa ganha mais espaço nas aulas de língua portuguesa" (Gênero resumo - LIMA; NASCIMENTO, 2009), em que o advérbio "Felizmente" imprime um posicionamento pessoal e axiológico positivo do locutor sobre o conteúdo do enunciado, pelo qual ele se apresenta como responsável;

b) avaliando o discurso alheio, de um segundo locutor introduzido no discurso, emitindo um posicionamento sobre o conteúdo da voz alheia e ao mesmo tempo indicando como o discurso do outro deve ser lido. Essa segunda

\footnotetext{
${ }^{9}$ O SE-locutor (omnilocutor, em espanhol, ou on-locutuer, em francês), nos estudos de Anscombre (2005, 2010), é definido como uma voz colocada em cena pelo locutor responsável pelo discurso e introduzida, geralmente, por marcadores de citação genéricos (segundo, diz-se etc.), que pode estar associada, em alguns contextos, à voz do conhecimento popular (nos provérbios, por exemplo) ou a uma voz coletiva, e nas quais o locutor enquanto ser do mundo ( $\lambda$ ) pode ou não estar incluído.
}

${ }^{10}$ Os modalizadores deônticos volitivos expressam, no sentido do enunciado, um desejo ou uma vontade, de caráter deôntico, segundo Nascimento e Silva (2012). Neves (2010), por sua vez, afirma que a modalidade volitiva ou bulomaica é, em sua profundidade, uma necessidade deôntica. 
ocorrência se deu, sobretudo, através de verbos dicendi modalizadores, como se observa nos trechos 06 e 07 , que seguem:

TRECHO 06 - Artigo Científico (BESSA, 2015)

Frade e Maciel (2006) ressaltam que as cartilhas são os primeiros livros de leitura, têm um ideal pedagógico e se constituem como a primeira via de acesso no processo de escolarização, ou seja, objetos de implementação da pedagogia da alfabetização (CACHIONI et al., 2015).

No trecho 06, retirado do corpus investigado por Bessa (2015), composto por artigos científicos, o locutor responsável pelo discurso como um todo ( $\mathrm{L} 1$ = locutor articulista) introduz em seu discurso o relato de outro locutor (L2 = Freire e Maciel) como fundamento para o seu dizer. O relato é apresentado em estilo indireto e introduzido pelo verbo dicendi modalizador avaliativo "ressaltam". Ao utilizar esse verbo, L1 não somente emite um posicionamento com relação ao discurso de L2, como também indica como esse discurso deve ser lido: como algo que merece ser ressaltado, logo, importante e digno de consideração. Dessa forma, avalia positivamente o discurso alheio e o incorpora ao seu dizer. Em outras palavras, poderíamos dizer que o efeito de sentido gerado no discurso é que o leitor tenha ciência de que o discurso apresentado em estilo indireto é de responsabilidade de L2, mas L1 está em conformidade com o mesmo, já que o apresenta como algo digno de ser ressaltado.

TRECHO 07 - Monografia de TCC (BASTOS, 2017)

Reconhecer um direito fundamental também exige do intérprete a observação dos limites expressos ao seu exercício. Todavia, a ideia de estabelecimento de restrição a direitos suscita uma problemática, pois, como bem adverte Friedrich Klein ${ }^{46}$, usando das leis da lógica, não pode existir restrição a direito individual, mas tão somente o conceito do que seja a mesma.

É possível observar, no trecho 07, retirado do corpus investigado por Bastos (2007), o uso da modalização avaliativa, utilizada para emitir um ponto de vista sobre um discurso de um segundo locutor introduzido no discurso. Segundo a pesquisadora, o trecho acima, coletado de uma monografia de TCC, inicia uma seção da referida monografia, problematizando a restrição de direitos individuais.

Como é possível perceber no referido trecho, o locutor responsável pela monografia (L1) inicia seu texto com o ponto de vista segundo o qual "Reconhecer um direito fundamental também exige do intérprete a observação dos limites expressos ao seu exercício". Em seguida, L1, por meio do operador de contraposição "todavia”, indica para o interlocutor uma mudança na orientação discursiva, apresentando o ponto de vista segundo o qual o estabelecimento de restrição a direitos provoca um problema.

Para fundamentar o ponto de vista introduzido pelo operador "todavia", L1 traz para o interior de seu discurso a voz de um segundo locutor (Friedrich Klein), introduzido pelo verbo dicendi modalizador avaliativo "advertir", acompanhado dos elementos "como" e "bem", compondo a expressão "como bem adverte".

Como observa Bastos (2017), o advérbio "como" normalmente indica conformidade com o ponto de vista introduzido, ou seja, um engajamento de L1 com relação ao discurso de L2. A noção de conformidade expressa pelo referido advérbio, como assinala Garcia Negroni (2008), pode ser reforçada pela presença do advérbio “bem”, em expressões do tipo "como bem disse x". No trecho 07 em análise, é possível verificar a ocorrência de tal fenômeno. Bastos (2017) afirma que há de se considerar que o advérbio "bem” é um modalizador avaliativo de sentido positivo e que, no trecho em análise, vem acompanhado por um dicendi também modalizador avaliativo: o verbo "advertir".

Com essa combinação, segundo Bastos (2017), L1 imprime um caráter avaliativo positivo ao ponto de vista apresentado, indicando que esse conteúdo deve ser lido como uma advertência. Esse caráter positivo é expresso pelo uso do advérbio "bem", que indica aprovação, algo que já estava sinalizado pelo emprego do advérbio "como", indicador de engajamento. Assim, L1 imprime um modo como o discurso de L2 deve ser lido, imprimindo um juízo de valor com relação ao discurso relatado, e ao mesmo tempo assimila esse discurso. 


\subsection{MODALIZADORES DELIMITADORES}

A modalização delimitadora é aquela que estabelece os limites dentro dos quais se deve considerar o conteúdo do enunciado e, por essa razão, identifica graus de tensão ou de negociação na interlocução, conforme assinalam Nascimento e Silva (2012).

Nos gêneros acadêmicos, este tipo de modalização não é muito usual, pelo menos nos corpora investigados. Sua maior recorrência se deu no gênero resumo acadêmico, investigado por Lima e Nascimento (2009), cujo funcionamento se pode perceber no enunciado que segue.

TRECHO 08 - Resumo (LIMA; NASCIMENTO, 2009)

Teoricamente, esperamos que os livros apresentem atividades que contemplem orientações atualizadas e sugiram formas de encaminhamento didático.

No trecho 08 , retirado de um resumo acadêmico, observa-se que, com a utilização do advérbio "teoricamente", o locutor estabelece limites para o conteúdo enunciado, ou seja, especifica-se que o conteúdo do dito (esperamos que os livros apresentem atividades que contemplem orientações atualizadas e sugiram formas de encaminhamento didático) deve ser encarado do ponto de vista teórico.

Isso pode implicar, por exemplo, que, do ponto de vista prático, pode ser que os livros não apresentem atividades que contemplem orientações atualizadas, mas do ponto de vista teórico é isso que se espera. Por esta razão, "teoricamente" funciona como um modalizador delimitador.

Os modalizadores delimitadores, nos gêneros acadêmicos, além de funcionarem estabelecendo limites dentro dos quais se deve considerar o conteúdo do tipo, agindo como elementos negociadores de sentido, muitas vezes especificam áreas de conhecimento, campos do saber ou aspectos que devem ser observados, com relação ao dito, imprimindo relativizações. Isso se dá em termos e expressões do tipo: "particularmente", "do ponto de vista pragmático", "no que se refere aos estudos da Psicologia Cognitiva”, entre outros.

\section{CONSIDERAÇÕES A RESPEITO DOS RESULTADOS OBTIDOS}

A investigação realizada nos gêneros acadêmicos descritos (resumo acadêmico, resenha acadêmica, projeto de pesquisa de TCC, monografia de TCC, artigo científico e ata administrativo-acadêmica) mapeou a presença de todos os tipos de modalizadores apresentados por Nascimento e Silva (2012): epistêmicos, deônticos, delimitadores e avaliativos. No entanto, são recorrentes apenas os modalizadores epistêmicos e avaliativos. Os demais (deônticos e delimitadores) são pouco frequentes e aparecem apenas em alguns dos gêneros, em especial no resumo e na ata administrativo-acadêmica.

No que se refere à modalização epistêmica, foram encontrados nos corpora os modalizadores asseverativos e quase-asseverativos; não houve ocorrência de modalizadores epistêmicos habilitativos. Os modalizadores asseverativos foram utilizados para imprimir asseveração ou noção de certeza, ou ainda para dar ideia de credibilidade ao dito, sempre comprometendo o locutor com relação ao conteúdo do enunciado/discurso. Os modalizadores epistêmicos quase-asseverativos foram utilizados para expressar possibilidade ou probabilidade. Na maioria dos casos, mas não sempre, o uso desse tipo de modalizador gerou distanciamento, não engajamento ou não comprometimento do locutor com relação ao conteúdo do enunciado.

A presença dos modalizadores epistêmicos nos gêneros acadêmicos é perfeitamente justificável se considerarmos que esses gêneros são utilizados para veicular a voz da ciência, que se pretende comprovada, certa, objetiva. Daí a forte presença dos modalizadores epistêmicos asseverativos, que apresentam o discurso como algo certo ou verdadeiro, em todos os gêneros pesquisados, inclusive no gênero ata administrativo-acadêmica. Os quase-asseverativos, por sua vez, permitem ao locutor dos gêneros acadêmicos colocarse à margem do dito, distanciando-se daquilo que enuncia, ou então apresentar investigações e dados ainda não comprovados e que, portanto, carecem de mais testagem ou análise. 
Os modalizadores avaliativos, frequentes em todos os gêneros investigados, foram utilizados para imprimir juízos de valor, avaliação axiológica, quase sempre de caráter positivo. Com esse tipo de modalizador, o locutor dos gêneros do universo acadêmico colocase em uma posição de quem analisa, se compromete e julga o seu dizer ou a voz da ciência. Além disso, podem sinalizar "engajamento" do locutor responsável pelo discurso com relação ao dizer de outros locutores introduzidos em seu texto.

É interessante observar que os modalizadores avaliativos e os modalizadores epistêmicos asseverativos ocorrem com grande frequência sob a forma de expressões ou verbos dicendi, que permitem ao locutor introduzir vozes alheias em seu próprio discurso - normalmente, sob a forma de arrazoado por autoridade; incorporar essas vozes; ou ainda emitir julgamentos com relação às vozes introduzidas. Nesse sentido, o discurso que se pretende objetivo e neutro torna-se um terreno de intercruzamento de vozes, de expressão de subjetividades. Isso significa, entre outras coisas, que o locutor responsável pelo discurso se permite expressar julgamentos sobre o fazer científico (seu e alheio) e se posicionar, enquanto sujeito, a respeito da voz da ciência.

A modalização deôntica, com baixa frequência nos corpora investigados, foi utilizada com dois principais efeitos de sentido: imprimir obrigatoriedade ou instrução + valor axiológico, através de modalizadores deônticos de obrigatoriedade, e expressar desejos ou solicitações (volição), através de modalizadores deônticos volitivos.

Acreditamos que essa baixa ocorrência se dá exatamente em razão da própria funcionalidade dos gêneros acadêmicos. Esses não são utilizados para normatizar, orientar ou instruir, uma vez que a ciência não se presta a esse fim, salvo algumas exceções, como é o caso da ata administrativo-acadêmica, que registra decisões tomadas nos conselhos acadêmicos. Em outras palavras, os gêneros acadêmicos descrevem, analisam e explicam fatos e fenômenos, à luz do conhecimento científico, sem preocupar-se necessariamente em regulamentá-los, salvo algumas exceções. Por esse motivo, não é um terreno propício para a presença dos modalizadores deônticos, tampouco para os modalizadores delimitadores, que também possuem grande caráter regulador, já que estabelecem limites dentro dos quais se deve considerar o conteúdo do dito. Talvez por esse motivo a ocorrência dos modalizadores delimitadores se deu, nos corpora analisados, principalmente em situações em que se fez necessária a delimitação de campos do saber, de áreas do conhecimento, apontando o alcance do fazer científico, em cada caso, especialmente.

As análises realizadas nos diversos gêneros do universo acadêmico permitiram verificar que a modalização discursiva, enquanto fenômeno de subjetividade e intersubjetividade (logo, argumentatividade), nesse universo de atividade humana, permite que o locutor responsável pelo discurso apresente o fazer da ciência como algo certo ou verdadeiro, o que contribui para a manutenção do status quo dessa atividade humana; coloque-se, algumas vezes, à margem do dito; mas também se posicione a respeito do próprio fazer científico, emitindo juízos de valor e orientando o seu interlocutor.

Nesse sentido, as investigações também nos fizeram refletir sobre a impessoalidade e a objetividade pregadas pelos manuais de redação científica. A utilização de diferentes tipos de modalização, materializando diferentes estratégias semântico-argumentativas nos textos, comprova que o fato de o texto científico ser apresentado, normalmente, na terceira pessoa do singular não implica objetividade, tampouco neutralidade, ou seja, a impessoalidade acaba sendo "neutralizada" por outras estratégias, como a modalização.

Assim, podemos afirmar que a argumentatividade (logo, subjetividade) se materializa, nos gêneros acadêmicos, entre outras estratégias, pelo uso da modalização. Isso significa que, através dos modalizadores, o locutor deixa marcas de sua subjetividade, avalia o dito e tenta orientar seu interlocutor, indicando como deve ser lida a voz da ciência.

\section{REFERENCIAS}

ADELINO, F. J. da S. Na trilha dos modalizadores: perscrutando os jogos argumentativos no gênero entrevista de seleção de emprego. 2016. 334 f. Tese (Doutorado em Linguística) - Programa de Pós-Graduação em Linguística, Universidade Federal da Paraíba, João Pessoa, 2016. 
BASTOS, A. C. V. De quem é essa voz? Um estudo sobre as marcas de subjetividade em monografias de conclusão de curso. 2017. 249 f. Tese (Doutorado em Linguística) - Programa de Pós-Graduação em Linguística, Universidade Federal da Paraíba, João Pessoa, 2017.

BARBOSA, M. V. L. de M. Modalização e polifonia no gênero resenha acadêmico-científica: um olhar argumentativo sobre a voz da ciência. 2015. 203 f. Tese (Doutorado em Linguística) - Programa de Pós-Graduação em Linguística, Universidade Federal da Paraíba, João Pessoa, 2015.

BESSA, C. M. B. Que autoridades sustentam a autoridade? A argumentatividade no gênero artigo científico através do arrazoado por autoridade e da modalização discursiva. 2015. 456 f. Tese (Doutorado em Linguística) - Programa de Pós-Graduação em Linguística, Universidade Federal da Paraíba, João Pessoa, 2015.

CARVAlHO, A. G. O arrazoado por autoridade e a modalização discursiva: estratégias de argumentação no gênero Projeto de Pesquisa de TCC. 2014. 147 f. Dissertação (Doutorado em Linguística) - Programa de Pós-Graduação em Linguística, Universidade Federal da Paraíba, João Pessoa, 2014.

CASTILHO, A. T. de; CASTILHO, C. M. M. de. Advérbios modalizadores. In: ILARI, R. (Org.). Gramática do Português Falado. v.II: níveis de análise linguística. 2. ed. Campinas: Editora da UNICAMP, 1993.

CHAVES, A. L. A. O sufixo -inho no gênero textual entrevista - elemento modalizador discursivo. In: SIMPÓSIO NACIONAL LINGUAGEM E GÊNEROS TEXTUAIS, 2007, João Pessoa. Anais... João Pessoa: Editora Universitária/EDUFPB, 2007. p. 1-19.

CERVONI, J. A enunciação. São Paulo: Ática, 1989.

DUCROT, O. O dizer o dito. Campinas: Pontes Editores, 1987.

Polifonia y argumentación: conferencias del seminario teoría de la argumentación y análisis del discurso. Cali: Universidad del Valle, 1988

ESPÍNDOLA, L. A entrevista: um olhar argumentativo. João Pessoa: Editora Universitária da UFPB, 2004.

GARCÍA NEGRONI, M. M. Os modos de dizer do sujeito no discurso acadêmico. Trad. Maria Eta Vieira. In: MICHELETTI, G. (Org.). Enunciação e gêneros discursivos. São Paulo: Cortez, 2008. p. 92-121.

KOCH, I. G. V. Argumentação e linguagem. 7. ed. São Paulo: Cortez, 2002. . A inter-ação pela linguagem. 11. ed. São Paulo: Contexto, 2012.

LIMA, G. de B.; NASCIMENTO, E. P. do. A argumentatividade no gênero resumo acadêmico: operadores argumentativos e modalizadores discursivos (Relatório de Pesquisa PIVIC). Mamanguape: Universidade Federal da Paraíba, 2009.

LYONS, J. Semantics. Cambridge: Cambridge University Press, 1977.

NASCIMENTO, E. P. do. Jogando com as vozes do outro: apolifonia - recurso modalizador - na notícia jornalística. 2005. 239 f. Tese (Doutorado em Letras) - Programa de Pós-Graduação em Letras, Universidade Federal da Paraíba, João Pessoa, 2005.

A modalização como estratégia argumentativa: da proposição ao texto. In: CONGRESSO INTERNACIONAL DA ABRALIN, 6., João Pessoa. Anais... João Pessoa: Editora Idéia, 2009. p. 1369-1376. CD-ROM. 
. A modalização deôntica e suas peculiaridades semântico-pragmáticas. Revista Fórum Linguístico, Florianópolis, v. 7, n. 1, p. 30-45, jan./jun. 2010. Disponível em: https://periodicos.ufsc.br/index.php/forum/article/viewFile/19848412.2010v7n1p30/17100. Acesso em: 12 jul. 2018.

. Modalización en el género "acta administrativo-académica”. (Relatório de Pesquisa de Estágio de Pós-doutorado) - Instituto de Lingüística, Universidad de Buenos Aires, Buenos Aires-Argentina, 2014.

. A polifonia nos gêneros acadêmicos e formulaicos: a construção de sentidos a partir da evocação da palavra alheia. Letras de Hoje, v. 50, n. 3, 2015. p. 242 - 351. Disponível em: http://revistaseletronicas.pucrs.br/ojs/index.php/fale/article/view/19385. Acesso em: 12 jul. 2018.

NASCIMENTO, E. P. do; SILVA, J. M. da. O fenômeno da modalização: estratégia semântico-argumentativa e pragmática. In: NASCIMENTO, E. P. do (Org.). A argumentação na redação comercial e oficial: estratégias semântico-discursivas em gêneros formulaicos. João Pessoa: Editora da UFPB, 2012.p. 63 - 100.

NEVES, M. H. de M. Texto e gramática. São Paulo: Contexto, 2010.

SANTOS, M. F. O. A modalidade no discurso de sala de aula, em contexto universitário. Revista do GELNE, v. 2, n. 2, p.1-5, 2000.

\section{(ㄷ) (1) $(9$}

Recebido em 25/05/2018. Aceito em: 12/07/2018. 